\title{
High Altitude Long Endurance Air Vehicle Analysis of Alternatives and Technology Requirements Development
}

\author{
Craig L. Nickol ${ }^{1}$ and Mark D. Guynn ${ }^{2}$ \\ NASA Langley Research Center, Hampton, VA 23681 \\ Lisa L. Kohout ${ }^{3}$ \\ NASA Glenn Research Center, Cleveland, OH 44135 \\ and \\ Thomas A. Ozoroski ${ }^{4}$ \\ Swales Aerospace, Hampton, VA 23681
}

\begin{abstract}
The objective of this study was to develop a variety of High Altitude Long Endurance (HALE) Unmanned Aerial Vehicle (UAV) conceptual designs for two operationally useful missions (hurricane science and communications relay) and compare their performance and cost characteristics. Sixteen potential HALE UAV configurations were initially developed, including heavier-than-air (HTA) and lighter-than-air (LTA) concepts with both consumable fuel and solar regenerative (SR) propulsion systems. Through an Analysis of Alternatives (AoA) down select process, the two leading consumable fuel configurations (one each from the HTA and LTA alternatives) and an HTA SR configuration were selected for further analysis. Cost effectiveness analysis of the consumable fuel configurations revealed that simply maximizing vehicle endurance can lead to a sub-optimum system solution. An LTA concept with a hybrid propulsion system (solar arrays and a hydrogen-air proton exchange membrane fuel cell) was found to have the best mission performance; however, an HTA diesel-fueled wing-body-tail configuration emerged as the preferred consumable fuel concept because of the large size and technical risk of the LTA concept. The baseline missions could not be performed by even the best HTA SR concept. Mission and SR technology trade studies were conducted to enhance understanding of the potential capabilities of such a vehicle. With near-term technology SR-powered HTA vehicles are limited to operation in favorable solar conditions, such as the long days and short nights of summer at higher latitudes. Energy storage system specific energy and solar cell efficiency were found to be the key technology areas for enhancing HTA SR performance.
\end{abstract}

\section{Nomenclature}

$\begin{array}{ll}\text { AoA } & =\text { Analysis of Alternatives } \\ \text { CI } & =\text { Compression Ignition } \\ \text { ERAST } & =\text { Environmental Research Aircraft and Sensor Technology } \\ \text { ESS } & =\text { Energy Storage System } \\ \text { HALE } & =\text { High Altitude Long Endurance } \\ \text { HTA } & =\text { Heavier-Than-Air } \\ \text { IC } & =\text { Intermittent Combustion } \\ \text { LCC } & =\text { Life Cycle Cost } \\ \text { LH }_{2} & =\text { Liquid Hydrogen }\end{array}$

\footnotetext{
${ }^{1}$ Aerospace Engineer, Aeronautics Systems Analysis Branch, MS 442, AIAA Senior Member.

${ }^{2}$ Aerospace Engineer, Aeronautics Systems Analysis Branch, MS 442, AIAA Senior Member.

${ }^{3}$ Senior Engineer, Electrochemistry Branch, MS 309-1.

${ }^{4}$ Aerospace Engineer, Swales Aerospace.
} 


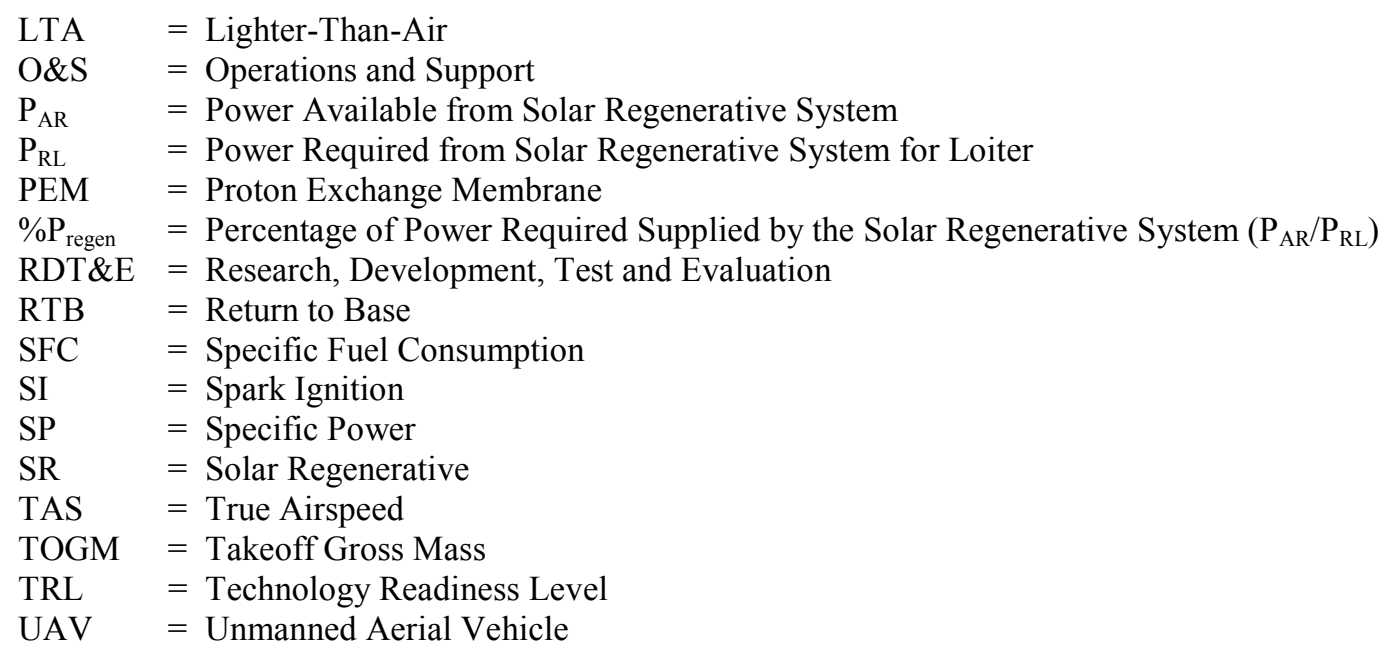

\section{Introduction}

Wigh Altitude Long Endurance (HALE) air vehicles have been the focus of significant research and development efforts for decades. ${ }^{1-6}$ The state of the art has been advanced to enable higher operational altitudes, longer durations with greater payloads, and increased autonomy. A wide variety of air vehicles, both operational and technology demonstration types, have been developed or are currently under development. Examples of high altitude and/or long endurance vehicles include the Boeing Condor; Northrop Grumman RQ-4 Global Hawk; AeroVironment Pathfinder, Helios, and Global Observer; and Scaled Composites Voyager and Global Flyer. The desire to extend the endurance of these vehicle types has led to research in solar regenerative (SR) propulsion systems relying on a solar photovoltaic array coupled to an energy storage system (ESS). SR propulsion systems are theoretically capable of propelling air vehicles to endurances of many months.

The purpose of this study was to benchmark the performance potential of HALE Unmanned Aerial Vehicle (UAV) concepts for operationally useful missions and to quantify the technology improvements required (if any) to enable these missions. Lighter-than-air (LTA) and heavier-than-air (HTA) concepts utilizing both SR and nonregenerative propulsion systems were analyzed. A secondary goal of this study was to develop and demonstrate a design and analysis capability for HALE UAV concept technical and feasibility assessments. The initial effort, termed Phase I, consisted of requirements derivation for the two missions, the identification and analysis of sixteen potential configurations, and a down select to the best HTA and LTA configurations. Phase II of the study consisted of an operational and life cycle cost analysis utilizing the feasible down-selected configurations. In addition, technology and mission requirements trade studies were performed for the preferred HTA SR configuration. This paper provides an overview and summary of the study results, more details can be found in reference 7 .

\section{Requirements}

The two reference missions utilized for this study were hurricane science and communications relay. HALE UAVs have been candidates for both of these mission types in past studies. A recent NASA study of the use of HALE UAVs for hurricane science is detailed in an unpublished white paper by M. Avery et al. ${ }^{8}$ According to this paper, the current Earth observing capability consists primarily of satellites and ground networks. Although aircraft missions also play an important role, their usefulness is limited by constrained durations, limited observation envelopes, and crew safety issues. A HALE UAV platform has the potential to overcome these constraints and provide measurements that complement the current space and ground based systems. The communications relay mission was selected to provide a commercial complement to the science driven hurricane mission. HALE UAV platforms have the potential to serve as effective, low cost communications relay systems due to their long endurance, large ground footprint (compared to cell phone towers), flexibility, and relatively low acquisition and operating costs (compared to satellites). 
Table 1. Summary of Requirements Evolution

\begin{tabular}{|c|c|c|c|c|c|c|c|c|}
\hline & \multicolumn{4}{|c|}{ Hurricane Science Mission } & \multicolumn{4}{|c|}{ Communications Relay Mission } \\
\hline & Initial & Phase I & \begin{tabular}{c|} 
Phase II \\
Threshold
\end{tabular} & Phase II Goal & Initial & Phase I & $\begin{array}{c}\text { Phase II } \\
\text { Threshold } \\
\end{array}$ & Phase II Goal \\
\hline Endurance (days) & $30-180$ & $30-180$ & 30 & 180 & $14-180$ & $14-180$ & 14 & 180 \\
\hline Payload Mass (kg) & $200-500$ & 400 & 200 & 350 & $136-200$ & 200 & 136 & 200 \\
\hline Payload Power (kW) & $1-2.5$ & 1.5 & 1 & 2.5 & $1-1.5$ & 1.5 & 1 & 1.5 \\
\hline Loiter Altitude $(\mathrm{km})$ & $21-21+$ & 21 & 18 & 21 & $18-21$ & 18 & 18 & 18 \\
\hline Dash Speed $(\mathrm{km} / \mathrm{h})$ & 150 & 150 & 110 & 150 & 200 & 200 & 200 & 200 \\
\hline Mission Dates & June-Nov & June-Nov & June-Nov & June-Nov & Year-Round & Year-Round & Year-Round & Year-Round \\
\hline Latitudes $\left({ }^{\circ} \mathrm{N}\right)$ & $10-30$ & $10-30$ & $10-30$ & $10-30$ & $25-47$ & $25-47$ & $25-47$ & $25-47$ \\
\hline Operating Base HTA & $\mathrm{n} / \mathrm{a}$ & Jacksonville & \multicolumn{2}{|c|}{ Jacksonville } & $\mathrm{n} / \mathrm{a}$ & Las Cruces & \multicolumn{2}{|c|}{ Las Cruces } \\
\hline Operating Base LTA & $\mathrm{n} / \mathrm{a}$ & Jacksonville & \multicolumn{2}{|c|}{ Lakehurst } & $\mathrm{n} / \mathrm{a}$ & Las Cruces & \multicolumn{2}{|c|}{ Lakehurst } \\
\hline Turn Around Time (hrs) & $\mathrm{n} / \mathrm{a}$ & $n / a$ & \multicolumn{2}{|r|}{8} & $\mathrm{n} / \mathrm{a}$ & $\mathrm{n} / \mathrm{a}$ & \multicolumn{2}{|r|}{8} \\
\hline A check interval (hrs) & $\mathrm{n} / \mathrm{a}$ & $\mathrm{n} / \mathrm{a}$ & \multicolumn{2}{|c|}{ HTA: 720 , LTA: 1 mission } & $\mathrm{n} / \mathrm{a}$ & $\mathrm{n} / \mathrm{a}$ & \multicolumn{2}{|c|}{ HTA: 720, LTA: 1 mission } \\
\hline A check time (hrs) & $\mathrm{n} / \mathrm{a}$ & $\mathrm{n} / \mathrm{a}$ & \multicolumn{2}{|c|}{ HTA: 48, LTA: 120} & $\mathrm{n} / \mathrm{a}$ & $\mathrm{n} / \mathrm{a}$ & \multicolumn{2}{|c|}{ HTA: 48, LTA: 120} \\
\hline C check interval (hrs) & $\mathrm{n} / \mathrm{a}$ & $\mathrm{n} / \mathrm{a}$ & \multicolumn{2}{|c|}{ HTA: 7200, LTA: 20000} & $\mathrm{n} / \mathrm{a}$ & $\mathrm{n} / \mathrm{a}$ & \multicolumn{2}{|c|}{ HTA: 7200, LTA: 20000} \\
\hline C check time (hrs) & $\mathrm{n} / \mathrm{a}$ & $\mathrm{n} / \mathrm{a}$ & \multirow{2}{*}{\multicolumn{2}{|c|}{336}} & $\mathrm{n} / \mathrm{a}$ & $\mathrm{n} / \mathrm{a}$ & \multirow{2}{*}{\multicolumn{2}{|c|}{336}} \\
\hline Attrition Interval (hrs) & $\mathrm{n} / \mathrm{a}$ & $\mathrm{n} / \mathrm{a}$ & & & $\mathrm{n} / \mathrm{a}$ & $\mathrm{n} / \mathrm{a}$ & HTA: 20000, LTA: 40000 & \\
\hline Assured Coverage & $\mathrm{n} / \mathrm{a}$ & $\mathrm{n} / \mathrm{a}$ & \multicolumn{2}{|c|}{ HTA: 20000 , LTA: 40000} & $\mathrm{n} / \mathrm{a}$ & $\mathrm{n} / \mathrm{a}$ & \multicolumn{2}{|r|}{ Yes } \\
\hline
\end{tabular}

The

vehicle requirements evolved during the course of the study. The initial set of requirements was derived from an examination of the two mission areas. Both threshold (minimum acceptable) and goal vehicle requirements were identified. A subset of these requirements was then used for Phase I, and, based on Phase I results and additional input, a refined set of requirements was developed for Phase II. The evolution of requirements is summarized in Table 1. A technology constraint was established for the study that all vehicle, payload, and ground operations technologies be at a Technology Readiness Level (TRL) $\geq 5$ by the end of fiscal year 2008 (FY08). TRL 5 is defined as component or breadboard validation in a relevant environment. ${ }^{9,10}$

\section{Phase I Analysis of Alternatives}

The configurations selected for Phase I of the study were grouped into two HTA categories and one LTA category. Table 2 presents the sixteen concepts studied during Phase I. HTA, consumable fuel concepts consisted of high aspect ratio wing-body-tail configurations with multiple propulsion options utilizing either liquid hydrogen $\left(\mathrm{LH}_{2}\right)$ or diesel fuel. The $\mathrm{LH}_{2}$-fueled propulsion options studied were spark ignition (SI) engine, gas turbine engine, proton exchange membrane (PEM) fuel cell, and Stirling cycle heat engine. A diesel-fueled compression ignition (CI) engine option was also included in the HTA consumable concepts. HTA SR planform configurations included all-wing, joined-wing, trussed-wing, and a variable geometry, multiple surface arrangement. Two energy storage options were studied, regenerative fuel cells and secondary batteries. The LTA concepts consisted of both consumable fuel and SR airships, plus an "aeroship" that obtains lift from both buoyant forces and aerodynamic forces. Several hybrid propulsion options were explored for both the LTA and HTA configurations, including several

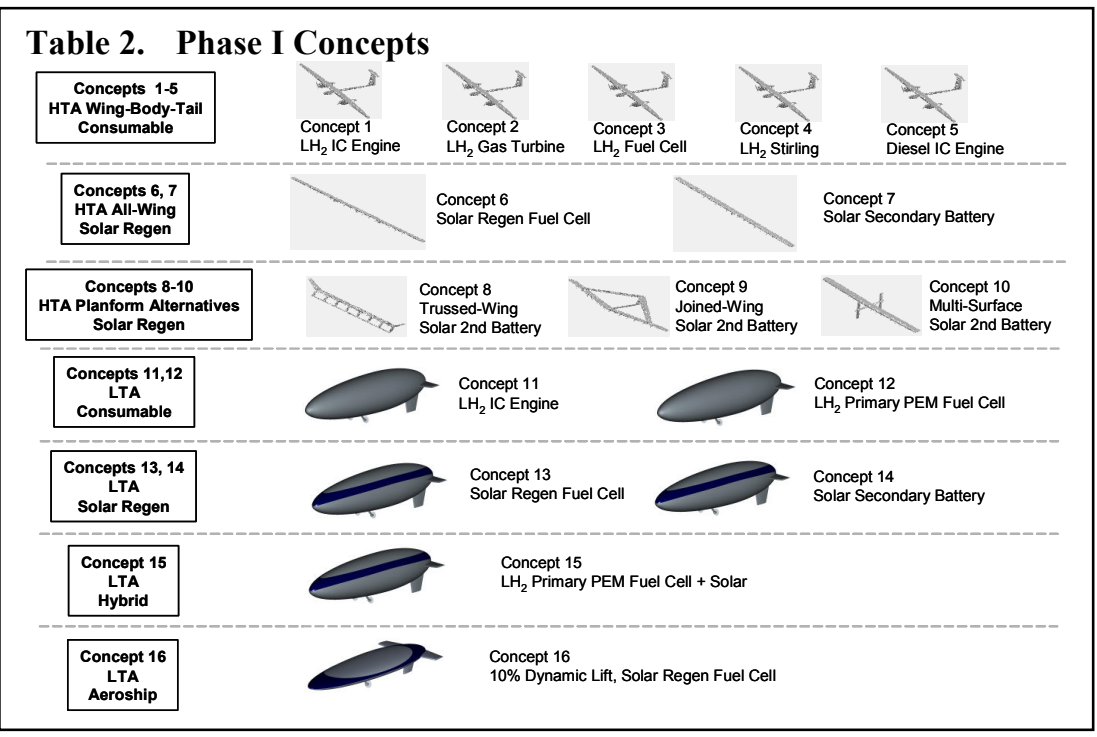
combinations of solar arrays with consumable fuel systems. Preliminary analysis indicated that solar-consumable hybrid propulsion systems are not attractive unless the consumable fuel (non-hybrid) mission endurance capability is very large (multiple weeks). Although beyond the endurance capability of the consumable fuel HTA configurations, such a large endurance is possible with the LTA configurations. Therefore, although hybrid propulsion HTA concepts were not developed, a hybrid propulsion LTA concept was developed (Concept 15) and included in the AoA.

\section{A. Tools and Methods}

The primary tool used to design and analyze the HTA vehicle concepts was a HALE Multi-disciplinary Design Optimization (MDO) code developed by AeroVironment, Inc. and delivered to NASA Dryden Flight Research 
Center in June of 2004. This HALE MDO code provides high-level, conceptual analysis and sizing of lightweight, low wing loading aircraft designed specifically for HALE missions. The code has the capability to address both consumable and SR propulsion systems. At NASA Langley the code was integrated into a commercially available software integration framework. Custom models and user interfaces were developed separately for consumable fuel and SR concepts based on the required inputs. Trade study and optimization features of the software integration framework were used throughout the study to explore the design space and optimize design variables. The HALE MDO code was validated for use in this HALE concept study with data from existing vehicles and past conceptual design studies. The Scaled Composites Voyager aircraft was used as one of the consumable fuel validation cases. In addition to validating overall performance estimates, outputs from individual subroutines of the code were also compared to existing vehicles and results of other design studies. Data used to evaluate accuracy of the subroutines included data from the Boeing Condor HALE UAV, the AeroVironment Pathfinder and Helios solar HALE UAVs, and a HALE propulsion study conducted by Boeing. ${ }^{6}$ For cases in which significant discrepancies were found between the code output and other data sources (e.g. fuselage/pod mass, propeller mass, cooling drag), appropriate calibration factors were determined and applied for the study analyses.

The primary tool used to design and analyze the LTA vehicle concepts was the Airship Design and Analysis Code (ADAC). ${ }^{11}$ ADAC is capable of performing rapid, vehicle level feasibility studies for HALE airship vehicles. ADAC was specifically designed to assess the feasibility of long endurance LTA vehicles required to perform station-keeping missions at altitudes between 16 and $22 \mathrm{~km}$. ADAC has been validated and calibrated at low altitudes using existing blimp data. Extrapolation to high altitude long endurance missions involves characterizing the likely advanced materials, power systems, and structural needs. This challenge was met by consulting discipline experts for perspective and guidance on choosing and implementing parameterized models of the systems and technologies.

The relative merits of the sixteen concepts were compared using a set of metrics developed as evaluation criteria. Common metrics such as endurance, mass, size, and risk were utilized. A new feasibility metric, "\% $\mathrm{P}_{\text {regen, }}$ " was created to enable comparison of the HTA SR concepts. This metric will be discussed further below.

\section{B. Concept Summary}

\section{Heavier-Than-Air Consumable Fuel Concepts (Concepts 1-5)}

\section{Concept 1 - $\mathbf{L H}_{2}$-Fueled Spark Ignition Intermittent Combustion Engine}

Concept 1 has a wing aspect ratio of 25.6, a wingspan of $80 \mathrm{~m}$, and twin engines contained in two wing pods which are sized by the spherical $\mathrm{LH}_{2}$ tank diameter. This concept utilizes an SI, intermittent combustion (IC) engine, fueled with $\mathrm{LH}_{2}$. The two primary metrics of interest for the propulsion system (specific fuel consumption (SFC) and specific power (SP)) were estimated using actual engine data with adjustments for the $21 \mathrm{~km}$ operating altitude and the use of $\mathrm{LH}_{2}$ fuel as described below.

Multiple stages of turbocharging are required for operation at $21 \mathrm{~km}$ due to atmospheric pressure lapse. In addition to the turbocharging, intercooling and aftercooling is required for the compressed air stream. Due to the low air density at loiter conditions, these components are larger than their lower altitude counterparts. During the NASA Environmental Research Aircraft and Sensor Technology (ERAST) program of the 1990's, significant progress was made with an operational aircraft using a doubly turbocharged Rotax 912 capable of producing 43.3 $\mathrm{kW}$ at $19.8 \mathrm{~km}$. Examining the ERAST Rotax 912 system in detail, the core engine and turbomachinery masses accounted for only $65 \%$ of the total system installed mass. The core engine mass accounted for only $48 \%$ of the total system mass. This historical information was utilized as a guide to estimate the ancillary masses required for the concepts in this study.

In addition to adjustments for operating altitude, adjustments must be made to account for the use of hydrogen fuel. Unlike conventionally fueled SI or CI engines, where the liquid fuel is sent into the cylinders and then vaporized, hydrogen must be sent into the engine in gaseous form due to its extremely low boiling point. This hydrogen gas displaces the air in the cylinders, effectively reducing air mass flow for the given geometric volume. This air mass flow reduction accounts for approximately a $10 \%$ reduction in maximum power. Hydrogen fuel also has a very fast flame propagation speed $(\sim 5$ times that of gasoline) and thus equivalence ratios greater than 0.65 produce detonation. For this reason, hydrogen-fueled IC engines must operate at a very lean equivalence ratio. This equivalence ratio reduction causes approximately a $30 \%$ power reduction. Because of these two factors, hydrogenfueled IC engines typically produce only about $60 \%$ of the power that their gasoline counterparts produce. In order to compensate for this power reduction, either a larger power plant (i.e., more core displacement) or increased inlet pressure is needed. Although using hydrogen reduces the power output of a given size engine, the benefit of hydrogen fuel is the large reduction in SFC associated with the higher specific energy $(\mathrm{W}-\mathrm{h} / \mathrm{kg})$ of hydrogen 
compared to hydrocarbon fuels. For long endurance missions, the additional power plant mass required for hydrogen-fueled propulsion is more than offset by the reduction in fuel mass required. The final SP estimate for the $\mathrm{LH}_{2}$-fueled SI IC engine was $222 \mathrm{~W} / \mathrm{kg}$, with an SFC of $80 \mathrm{~g} /(\mathrm{kW}-\mathrm{h})$. The hurricane science mission total endurance for Concept 1 was 7.9 days, with a $253 \mathrm{~km} / \mathrm{h}$ true airspeed (TAS) during loiter. These figures were 10.0 days and $197 \mathrm{~km} / \mathrm{h}$ for the communications relay mission.

\section{Concept 2 - $\mathrm{LH}_{2}$-Fueled Gas Turbine Engine}

Concept 2 utilizes the same airframe configuration as Concept 1, but uses a $\mathrm{LH}_{2}$-fueled gas turbine engine instead of an IC engine propulsion system. Gas turbine engines operate at considerably less than stoichiometric fuel-to-air ratios; therefore, large amounts of air are needed for their operation. At $21 \mathrm{~km}$ this can be addressed with large propellers and air intakes. Many studies have been performed to develop estimates for the mass and SFC of such a propulsion system designed for high altitude aircraft. One such engine is a scaled derivative of the T406 Allison engine. ${ }^{12}$ Based on this derivative engine, a specific power of $425 \mathrm{~W} / \mathrm{kg}$ and SFC of $116 \mathrm{~g} /(\mathrm{kW}-\mathrm{h})$ were assumed for the $\mathrm{LH}_{2}$ gas turbine propulsion system. The hurricane science mission total endurance for Concept 2 was 6.3 days, with a $243 \mathrm{~km} / \mathrm{h}$ TAS during loiter. These figures were 9.1 days and $189 \mathrm{~km} / \mathrm{h}$ for the communications relay mission.

\section{Concept 3 - $\mathbf{L H}_{2}$-Fueled PEM Fuel Cell and Electric Motor}

This concept utilizes the same airframe configuration as the previous two concepts, but uses an electric propulsion system consisting of a PEM fuel cell and electric motor. Hydrogen (stored as liquid) and atmospheric air are the fuel cell reactants. Compared to combustion engines, fuel cells typically have lower specific power (higher mass), but due to their higher conversion efficiencies they also have lower specific fuel consumption. One factor that affects fuel cell performance, especially for HALE UAV applications, is operating pressure. Higher pressures improve performance, but at the expense of increased mass and power penalties due to the added compressors. Most PEM H$~_{2}$-air stacks are designed to operate at $\sim 100 \mathrm{kPa}$ as dictated by the commercial market (ground-based applications).

A previous, unpublished study by George Turney examined the overall specific power of a fuel cell subsystem for a high altitude aircraft $(19.8 \mathrm{~km}){ }^{13}$ Although Turney considered an alkaline fuel cell, the specific power of the PEM fuel cell technology at that time was fairly close to the alkaline system, and thus his results can serve as a data point for consideration. The overall specific power of the system, which included the fuel cell, ancillaries, turbocharger, etc., was estimated to be $185 \mathrm{~W} / \mathrm{kg}$ with an SFC of $61 \mathrm{~g} /(\mathrm{kW}-\mathrm{h})$. As with the combustion engines, the PEM fuel cell turbomachinery and heat exchanger masses will increase at higher altitudes. The change in altitude from $19.8 \mathrm{~km}$ to $21 \mathrm{~km}$ resulted in roughly a $20 \%$ increase in the component masses for the combustion engine systems. Since these components will be similar for the fuel cell system, a $20 \%$ increase in turbomachinery and heat exchanger mass was also assumed for the fuel cell system to account for operation at $21 \mathrm{~km}$ rather than $19.8 \mathrm{~km}$. After adjustment for the higher operational altitude, the estimated specific power decreased to $164 \mathrm{~W} / \mathrm{kg}$. The SFC was also adjusted from $61 \mathrm{~g} /(\mathrm{kW}-\mathrm{h})$ to $57 \mathrm{~g} /(\mathrm{kW}-\mathrm{h})$ to remove the effect of electric motor losses, which were included in the SFC of the Turney study but are accounted for separately in the HALE MDO code. The hurricane science mission total endurance for Concept 3 was 7.6 days, with a $251 \mathrm{~km} / \mathrm{h}$ TAS during loiter. These figures were 9.9 days and $195 \mathrm{~km} / \mathrm{h}$ for the communications relay mission.

\section{Concept $4-\mathrm{LH}_{2}$-Fueled Stirling Engine}

This concept utilizes the same airframe configuration as the previous three concepts. The propulsion system is a Stirling engine using $\mathrm{LH}_{2}$ and atmospheric air as reactants. Recently designed Stirling converters have achieved greater than $60 \%$ of the Carnot efficiency, and at the temperature ratios possible with the very cold upper atmosphere, overall efficiencies of $47 \%$ (not including the burner or power conversion) may be achievable. One challenge with Stirling converters is transferring the heat into the device. In order to keep the heat transfer area reasonable, the air passed over the heater head into the combustor should be near a pressure of one atmosphere. To accomplish this several stages of turbocharging can be used as for IC engines. The major downside to Stirling converters that has curtailed their use in aircraft is their relatively low specific power. Using superalloy materials, a specific power of $200 \mathrm{~W} / \mathrm{kg}$ should be achievable for a $50 \mathrm{~kW}$ system. This is about two thirds the value of a spark ignition engine. Adding similar ancillaries to the system as needed for the IC engine systems (radiator, intercoolers, etc.), specific powers of approximately $162 \mathrm{~W} / \mathrm{kg}$ are likely. This combination of high power plant mass but reasonable efficiency could still lead to an attractive system since the burners can operate on jet fuel, diesel, or hydrogen. The estimated SFC at $21 \mathrm{~km}$ assuming $\mathrm{LH}_{2}$ fuel is $102 \mathrm{~g} /(\mathrm{kW}-\mathrm{h})$. The hurricane science mission total

endurance for Concept 4 was 5.0 days, with a $242 \mathrm{~km} / \mathrm{h}$ TAS during loiter. These figures were 5.8 days and 188 $\mathrm{km} / \mathrm{h}$ for the communications relay mission. 


\section{Concept 5 - Diesel-Fueled Compression Ignition Intermittent Combustion Engine}

The propulsion system for this concept is a conventional CI engine using diesel fuel. The airframe configuration layout is the same as the previous four concepts except that the diesel fuel is stored in the wing rather than in spherical tanks like the $\mathrm{LH}_{2}$ fuel. CI engines differ from SI engines in two important ways with respect to their use for HALE applications. First, by use of higher compression ratios, CI engines are more efficient at removing energy from the fuel that is injected into the cylinders. A typical efficiency value for a naturally aspirated 4-stroke SI engine is about $34 \%$ compared to almost $40 \%$ for a $\mathrm{CI}$ engine. This increase in efficiency means more of the useful work is extracted from the cycle resulting in less energy in the exhaust for turbocharging. The second difference with respect to HALE applications is that CI engines use excess air and thus the exhaust temperatures are further reduced. SI engines operate near ideal stoichiometric conditions, or equivalence ratios of 1.0, to match the fuel-toair ratio. CI engines require excess air to operate lean with a maximum equivalence ratio of about 0.6 . This lower equivalence ratio prevents engine smoking, which is not environmentally acceptable. Based on historical diesel engine data and the additional equipment required for high altitude operation, specific power of the diesel-fueled CI engine was estimated to be $263 \mathrm{~W} / \mathrm{kg}$ and the SFC was estimated to be $183 \mathrm{~g} /(\mathrm{kW}-\mathrm{h})$. The hurricane science mission total endurance for Concept 5 was 5.7 days, with a $250 \mathrm{~km} / \mathrm{h}$ TAS during loiter. These figures were 6.5 days and $195 \mathrm{~km} / \mathrm{h}$ for the communications relay mission.

\section{Heavier-Than-Air Solar Regenerative Concepts (Concepts 6-10)}

The basic idea of SR propulsion is that the sun can be the sole energy source for the vehicle. During the day some of the energy collected by the solar cells is used to power the propulsion system, payload, and other on-board systems. Excess energy collected above that required to operate the vehicle is used to charge an energy storage system. At night the vehicle is powered by discharging the energy storage system. If the system is balanced over a diurnal cycle (energy collected from the sun equals energy required to fly plus losses), then the vehicle can theoretically remain aloft indefinitely. There are a number of different ways to store energy such as secondary (i.e., rechargeable) batteries, flywheels, regenerative fuel cells, or even altitude.

Preliminary analysis of the SR concepts quickly revealed that none would have sufficient performance to conduct either the hurricane science mission or the communications relay mission. The SR propulsion system, given the assumptions made for the analysis, could not provide the amount of power on a continuous basis needed to operate the vehicle. Since the missions were not feasible for any of the concepts, traditional metrics such as endurance and takeoff mass could not be used to compare the HTA SR concepts. Instead, the metric used to compare the concepts was the percentage of the total power required to fly the vehicle which could be provided by the $\mathrm{SR}$ system, referred to as $\% \mathrm{P}_{\text {regen }}$.

$\% \mathrm{P}_{\text {regen }}$ is a measure of mission feasibility calculated from the ratio of two parameters, $\mathrm{P}_{\mathrm{AR}}$ and $\mathrm{P}_{\mathrm{RL}} . \mathrm{P}_{\mathrm{AR}}$ is the power available from the SR system which can be provided continuously with no net loss in "state-of-charge" at the end of 24 hours. In other words, this is the power level which can be energy balanced for a given SR power system. The SR power system consists of the solar arrays, energy storage system, and associated auxiliary equipment. The value of $\mathrm{P}_{\mathrm{AR}}$ depends on flight latitude and time of year, solar array size, solar array efficiency, power management and distribution efficiency, energy storage system efficiency, and energy storage system capacity. $P_{R L}$ is the power required from the SR power system during loiter; comprised of power needed for propulsion and power needed for the payload and aircraft systems. The payload power required and aircraft system power required are fixed inputs to the analysis. The propulsion power required is a function of the total aircraft mass, the aerodynamic efficiency (liftto-drag ratio), flight speed, propeller efficiency, and motor efficiency. If $\mathrm{P}_{\mathrm{AR}}$ divided by $\mathrm{P}_{\mathrm{RL}}$ is greater than 1.0 $(100 \%)$, the specified mission is feasible since the SR power system can provide the power required to fly the vehicle and maintain a diurnal cycle energy balance. Values less than 1.0 indicate the mission is infeasible. Note that $P_{R L}$ is not independent of the characteristics of the $S R$ power system since total aircraft mass includes the mass of the SR power system. Maximizing $\mathrm{P}_{\mathrm{AR}}$ does not necessarily maximize the ratio of $\mathrm{P}_{\mathrm{AR}}$ to $\mathrm{P}_{\mathrm{RL}}$ because increasing solar array size or energy storage system capacity also increases $\mathrm{P}_{\mathrm{RL}}$. Maximizing the ratio, $\% \mathrm{P}_{\text {regen }}$, was the objective used to size the SR system and optimize the vehicle designs.

\section{Concept 6 - All-Wing Configuration with Solar Regenerative Fuel Cell Propulsion}

Concept 6 represents a baseline approach for the SR vehicles. The all-wing design has heritage in the family of solar-electric aircraft built by AeroVironment before and during NASA's ERAST program (Pathfinder, Pathfinder Plus, and Helios). All of these vehicles utilized distributed electric propulsion systems with numerous propellers driven by electric motors. Use of a regenerative fuel cell system was researched under the ERAST program and such a system was designed for the Helios aircraft, although never completed. In a solar regenerative fuel cell system, the energy is stored as hydrogen and oxygen reactants. At night the reactants are combined in a fuel cell 
producing heat, water, and electricity to power the vehicle. During the daytime excess energy from the sun is used to electrolyze the water back into $\mathrm{H}_{2}$ and $\mathrm{O}_{2}$ which is then stored for use at night, forming a closed-loop system. Regenerative fuel cell systems can utilize separate systems for the power generation (fuel cell) and water electrolysis (electrolyzer) or a single unitized system which performs both functions. For Concept 6 separate fuel cell and electrolyzer systems were used due to the lower level of technology maturity for the unitized system.

Propulsion system assumptions for Concept 6 were based on characteristics of the AeroVironment Helios design and test data from NASA Glenn Research Center. The solar array incorporates high efficiency, bi-facial silicon solar cells of the type used on Helios. Solar cell reference efficiency was assumed to be $20 \%$. This efficiency is representative of an individual solar cell at a reference condition. The HALE MDO code accounts for variation in efficiency due to cell temperature and includes an array power scaling factor for wiring losses and other miscellaneous losses associated with installation of individual solar cells into a solar array. The fuel cell and electrolyzer polarization data (voltage versus current density) were derived from tests at NASA Glenn on the Lynntech Gen IV system. ${ }^{14}$ Although Concept 6 borrows significantly from Helios heritage the vehicle size is much larger. A maximum wingspan constraint of $100 \mathrm{~m}$ was assumed for this study and best overall performance of the design was obtained at that wingspan. Despite the large wingspan, the wing aspect ratio is relatively low compared to Helios. Optimum wing area was found to be approximately $600 \mathrm{~m}^{2}$ resulting in an aspect ratio of only 16.7. The resulting wing loading is similar to Helios. For the hurricane science mission $\% \mathrm{P}_{\text {regen }}$ for Concept 6 was only $31 \%$. For the communications relay mission $\% \mathrm{P}_{\text {regen }}$ was even less at $26 \%$.

\section{Concept 7 - All-Wing Configuration with Solar Secondary Battery Propulsion}

Concept 7 differs from Concept 6 primarily in the type of energy storage system used. For Concept 7, energy is stored in rechargeable batteries (also referred to as secondary batteries). Secondary batteries are superior to regenerative fuel cell systems in terms of roundtrip efficiency, defined as the amount of energy extracted from the system when it is discharged compared to the amount of energy expended to charge the system. Roundtrip efficiencies for regenerative fuel cell systems are on the order of $50 \%$ whereas some batteries can achieve efficiencies greater than $90 \%$. The drawback of secondary batteries is the higher mass required to store a given amount of energy (i.e., lower specific energy, $\mathrm{W}-\mathrm{h} / \mathrm{kg}$ ). Because of their efficiency, however, batteries need not have a specific energy as high as regenerative fuel cells in order to result in better overall aircraft performance. Lithium-Ion is one type of rechargeable battery which is currently used widely in a variety of applications. A different type of battery that theoretically provides higher specific energy is Lithium-Sulfur. ${ }^{15}$ Near-term projected Li-S technology served as the basis for the battery assumptions used in Concept 7. After accounting for depth-ofdischarge and power management efficiencies, a specific energy of $252 \mathrm{~W}-\mathrm{h} / \mathrm{kg}$ and roundtrip efficiency of $82 \%$ was used in the analysis. Concept 7 had a $\% \mathrm{P}_{\text {regen }}$ of $36 \%$ for both the hurricane science and communications relay missions.

\section{Concept 8 - Trussed-Wing Configuration with Solar Secondary Battery Propulsion}

Concepts 8 through 10 represent an attempt to evolve beyond the Helios-like, all-wing configuration and use more unconventional designs to address some of the known problems with past HALE SR vehicles. One well known problem with the Helios design was its high degree of flexibility. One way to limit flexibility is to use a trussed-wing structure as in Concept 8 . In addition to providing rigidity to the structure, the pylons in Concept 8 provide a vertical surface for solar arrays. When operating at high latitude in winter months, the sun is very low on the horizon and vertical arrays can provide a more optimum angle relative to the sun than horizontal (wing) arrays. One drawback of the Concept 8 design is a reduction in aerodynamic performance due to the drag of the truss structure.

Analysis of Concept 8 revealed that vertical solar arrays do not always provide a significant energy benefit. Although offering the potential for a more direct solar incidence angle when the sun is low in the sky, performance of vertical arrays suffer from a directionality issue. For example, a vertical array facing east at sunrise would benefit from a near normal sun angle and produce much more solar power than a horizontal array. However, by the afternoon that array is facing away from the sun and collecting no energy. Because the design missions are loiter missions and the aircraft heading is constantly changing, a given vertical array spends only a fraction of the day at an optimal or near optimal angle with the sun.

Feasibility of both the hurricane science mission and communications relay mission was slightly less for Concept 8 than Concept 7 ( $\% \mathrm{P}_{\text {regen }}$ of $31 \%$ and $35 \%$ respectively). A number of the areas in which the trussed-wing design would show potential for improvement over the cantilever wing designs were not addressed in the high level analysis conducted for the AoA. In some respects the analysis conducted highlighted the penalties of the concept without fully exploring the benefits. Even so, these benefits would not be enough to overcome the limitations of current technology SR propulsion and achieve feasibility of the hurricane science or communications relay missions. 


\section{Concept 9 - Joined-Wing Configuration with Solar Secondary Battery Propulsion}

Another unconventional layout considered was a joined-wing configuration. The joined-wing was expected to provide an increase in structural rigidity and perhaps a reduction in total structural mass compared to the all-wing arrangement. Another motivation for the joined-wing approach was to obtain a large amount of solar array area in a more compact design. Because "compactness" was one of the desires for the joined-wing concept, the span of Concept 9 was limited to $80 \mathrm{~m}$. Modeling this type of design with the available analysis tools required an extensive set of simplifying assumptions. Predicted wing spar mass was checked with a structural analysis code developed specifically for joined-wing configurations based on inextensible beam theory. ${ }^{16}$ Good agreement was obtained between the predicted mass and the more detailed structural analysis. The simplified modeling did not fully address all of the penalties associated with a joined-wing design such as a heavier vertical tail than a conventional design. Past evaluations of joined-wing designs have shown structural mass benefits compared to conventional wing-bodytail designs. It is not clear, however, that a joined-wing design would have structural mass benefits compared to an all-wing design in which the tail mass and fuselage mass have been eliminated. $\% \mathrm{P}_{\text {regen }}$ for Concept 9 was $29 \%$ for both the hurricane science and communications relay missions.

\section{Concept 10 - Multi-Surface Configuration with Solar Secondary Battery Propulsion}

The amount of solar energy collected during the day is greatly reduced by non-optimal array orientation. Solar energy collection is maximized when the array is normal to the incident solar rays and decreases with the sine of the incidence angle. As noted in the discussion of Concept 8 , because the aircraft heading and orientation relative to the sun is continually changing, an array that is fixed on the aircraft will be in an optimum orientation for only a fraction of the day. Concept 10 was developed in an attempt to address the problem of solar array orientation. The basic idea of this concept is to have arrays which re-orient throughout both the loiter pattern and the day to maximize the solar energy collected (the arrays only vary in roll angle, not pitch and yaw). Unlike the vertical arrays in Concept 8 , a sun-tracking array will always perform better than a horizontal array no matter what the latitude and time of year. The magnitude of the benefit, however, does vary with time of year and latitude, with a maximum in wintertime at high latitudes when it is most needed. For the communications relay mission worst solar conditions $\left(47^{\circ} \mathrm{N}\right.$, December 21$)$ and a circular loiter pattern, a sun-tracking array can collect more than 2.5 times the energy of a horizontal array, assuming it is positioned at the optimum roll angle at each point in time. It is not possible to roll the entire wing to perform the sun-tracking function since the wing still must produce sufficient lift in the "up" direction to maintain level flight. In Concept 10 auxiliary surfaces are used which are not intended to provide any contribution to lift or control of the vehicle, but rather whose sole purpose is to be positioned for maximum energy collection. The stability and controllability of the vehicle will vary with auxiliary surface position, however. Addressing the stability and control issues introduced by the auxiliary surfaces was beyond the scope of this study. Although these surfaces provide additional energy with much greater effectiveness than the horizontal wing array, they also add mass and drag to the configuration without any lift benefit. The mass and drag of these surfaces were accounted for in the analysis by modeling them as tail surfaces. An additional mass and power penalty was added to account for the mechanism required to rotate the surfaces. The size of the auxiliary surfaces was optimized for the worst case solar conditions of each mission. The resulting $\% \mathrm{P}_{\text {regen }}$ was $35 \%$ for the hurricane science mission and $40 \%$ for the communications relay mission.

\section{Lighter-Than-Air Concepts (Concepts 11-16)}

Airship sizing is dominated by the loiter altitude and the winds that must be overcome to remain on station. Wind speed dictates the size of the propulsion system and loiter altitude determines the volume of lifting gas required. For this study the maximum design speed of the airships was set by the highest wind speed $\left(99^{\text {th }}\right.$ percentile) encountered during any mission. The required transit speed from base to the mission site defined a minimum design cruise speed, which could possibly exceed the mission maximum wind speed. However, for both missions of this study the transit speed was less than the mission maximum wind speed. The $99^{\text {th }}$ percentile wind speed is not actually encountered during many simulated mission sorties, but usually exists for short durations when it is encountered. The propulsion system was sized to meet the power required at the maximum design speed, but a volume constraint was applied to limit the vehicle to an acceptable size. The volume constraint was $415,000 \mathrm{~m}^{3}$, which is about $80 \%$ of the size of existing hangar facilities. For comparison, the volume of the Goodyear blimp Eagle is $5740 \mathrm{~m}^{3}$ ( $59 \mathrm{~m}$ long and $15 \mathrm{~m}$ wide) and the volume of the Hindenburg was 212,000 $\mathrm{m}^{3}$ (245 $\mathrm{m}$ long, $41 \mathrm{~m}$ wide).

The hull and ballonet fabric type and thickness affect a significant portion of the mass of the vehicle, so it is important to ensure that this part of the design is reasonably modeled. The basic problem is to determine the fabric type and thickness based on the amount of structural stiffening and internal pressure required to maintain the vehicle 
shape. Complications to this problem include the need for seams and stitching; UV protection; coatings to prevent lifting gas leakage; avoiding cracks, wrinkles, and delamination; temperature tolerance; minimizing elongation under strain; and applying reasonable factors of safety. Two lightweight fabric materials commonly known for high specific strength are Kevlar ${ }^{\circledR}$ and Spectra ${ }^{\circledR}$. $\operatorname{Kevlar}^{\mathbb{B}}$ has poor abrasion resistance and flex cracking characteristics, which limits airship applications due to the need for inflation and handling. Spectra ${ }^{\circledR}$ fiber has one of the highest strength-to-weight ratios of any man-made fiber and is also highly resistant to flex fatigue and UV light. ${ }^{17}$ Other fabrics considered in Phase I were sufficiently limited in one or more categories as to be eliminated. Therefore, Spectra ${ }^{\circledR}$ was assumed for the Phase I concepts.

Many of the differences among the airship concepts are associated with the choice of power and energy systems to meet the vehicle power demand as a function of time throughout the mission. These choices set the masses of the propulsion system, fuel tanks, fuel, solar cells, regenerative equipment, and batteries. For this reason, it is important to track the power demands and energy balance of the vehicle over short time intervals as the vehicle is subjected to changing wind speed and solar energy flux. The power is time integrated over the entire mission to ensure that the energy balance cycle closes at either the end of the mission or at the most demanding point of the mission. The power systems used for the LTA concepts included the $\mathrm{LH}_{2}$-fueled IC engine (Concept 11), the $\mathrm{LH}_{2}$-fueled PEM fuel cell system (Concept 12), the SR fuel cell system (Concepts 13 and 16), the SR secondary battery system (Concept 14), and a solar-PEM fuel cell hybrid system (Concept 15). The propulsion system assumptions used for the LTA concepts were identical to those in the HTA analysis except that thin film flexible solar arrays were utilized for the LTA concepts.

All of the LTA Concepts were able to meet the full 180 day endurance requirement for the hurricane science mission. Concept 13 (SR fuel cell airship) had the lowest mass of the LTA concepts when designed for the hurricane science mission. The SR fuel cell aeroship concept (Concept 16) was heavier and larger than the traditional SR fuel cell airship concept. Although attractive for the hurricane science mission, the SR concepts (Concept 13, 14, and 16) were not attractive for the communications relay mission, having the highest mass and volume, and endurance capability lower than the non-regenerative concepts. For the consumable and hybrid propulsion configurations (Concepts 11, 12, and 15), endurance for the communications relay mission varied from about 30 days to 180 days depending on the mission start date. (LTA endurance is sensitive to mission start date due to seasonal changes in winds aloft.) Concept $11\left(\mathrm{LH}_{2}\right.$-fueled IC engine) had the lowest mass and volume for the communications relay mission design.

\section{Phase I Down Select Results}

Based on the AoA metric results, a concept down select was performed. The primary discriminator used was endurance, with consideration given to the other metrics as well, particularly takeoff gross mass and risk. Although none of the HTA consumable concepts met the threshold endurance requirement for either mission, Concept $1\left(\mathrm{LH}_{2}-\right.$ fueled IC engine propulsion) showed the greatest endurance, closely followed by Concept 3 ( $\mathrm{LH}_{2}$-fueled PEM fuel cell and electric motor). However, Concept 3 ranked higher in risk, due primarily to the relatively complex and unproven propulsion system. In addition, the takeoff gross mass for Concept 3 was higher in both missions. Therefore, Concept 1 was selected for the Phase II operational study and cost analysis.

As previously mentioned, none of the HTA SR concepts could close for either of the two study missions. That is, the SR system could not provide sufficient energy even on the most favorable day-night cycle of the required mission period. Concept 7 (all-wing, secondary battery) and Concept 10 (multi-surface, secondary battery) had the highest $\% \mathrm{P}_{\text {regen }}$ values; however, in neither case was the SR system able to supply more than half of the power required. Although Concept 10 had better performance than Concept 7 on the communications relay mission, the performance benefit was too small to justify the added complexity of the variable geometry surfaces. These surfaces did not provide a net benefit for the hurricane science mission due to the lower latitudes of the operational area. Therefore, Concept 7 was selected for Phase II of the study. For this concept, technology and mission requirements trade studies were conducted for Phase II since an operational and cost analysis of an infeasible concept was deemed of little value.

Similar to the HTA consumable concepts, the LTA concepts with the best performance were Concept $11\left(\mathrm{LH}_{2}\right.$ fueled IC engine) and Concept $12\left(\mathrm{LH}_{2}\right.$-fueled PEM fuel cell and electric motor). The endurance of these concepts was sufficient to complete the full hurricane science mission, and, depending on the time of year, a large part of the communications relay mission. However, the feasibility of operating the IC engine of Concept 11 continuously over the entire six-month mission is questionable. The oil supply required by the IC engine for lubrication and cooling would deplete over time. The engine would have to be designed to minimize oil depletion or the oil would have to be replenished during the mission. In addition, the mechanical components of the IC engine would have to perform over endurances not typical for aviation applications. Concept 12, utilizing a PEM fuel cell, avoids these issues. 
None of the LTA SR concepts were attractive due to their lack of endurance and large size and mass for the communications relay mission. The LTA hybrid PEM fuel cell plus solar array system of Concept 15 showed promising performance. (A hybrid IC engine plus solar array concept was not investigated due to the extreme endurance issues with the IC engine noted above.) The performance of Concept 15 was similar to that of Concept 12, but Concept 15 was smaller in size and mass $\left(124,500 \mathrm{~m}^{3}\right.$ and 12,900 $\mathrm{kg}$ for Concept 15 versus 136,800 $\mathrm{m}^{3}$ and $15,600 \mathrm{~kg}$ for Concept 12). Therefore, Concept 15 was selected for the Phase II operational study and cost analysis.

\section{Phase II Analysis}

\section{A. Operational Concept Study}

Three HTA consumable fuel configurations were developed for the Phase II analysis. Concept 1 was re-sized to the hurricane science mission Phase II goal requirements, which, compared to Phase I requirements, reduced payload mass by $50 \mathrm{~kg}$ but increased payload power by $1 \mathrm{~kW}$ to $2.5 \mathrm{~kW}$ (see Table 1). The resulting $80 \mathrm{~m}$ span vehicle had a slightly reduced takeoff gross mass. Optimized for maximum endurance, the endurance capability of Concept 1 on the hurricane science mission was 8.1 days. Endurance capability on the communications relay mission was 10 days. To support the operational concept study, Concept 1 was also re-sized to a 4-day endurance for the hurricane science mission. The resulting vehicle, termed "Concept 1-small," had a $46 \mathrm{~m}$ wingspan, had less than half the mass of the $80 \mathrm{~m}$ wingspan vehicle, and used about one-third the fuel. The final HTA vehicle utilized to support the operational concept study was a re-sized version of Concept 5, the diesel-fueled IC engine configuration. "Concept 5-small" was also sized to a 4-day endurance for the hurricane science mission, resulting in a vehicle with a fuel load less than half of Concept 5, a gross mass a little more than half of Concept 5 , and a $58 \mathrm{~m}$ wingspan. These two additional "small" concepts were developed to assess the sensitivity of the system life cycle cost to vehicle endurance.

The down selected LTA design, Concept 15, was also further refined for the cost and operations study. Most of the changes were based on an in-depth review of the hull fabric parameters and the hull construction techniques. In addition to Spectra $^{\circledR}$, fabrics considered for Phase II included 710 polyester by Celanese Corporation and Vectran ${ }^{\mathrm{TM}}$ HS. 710 polyester is a standard fabric used for airships, aerostats, and logging balloons. Compared to 710 polyester, Vectran ${ }^{\mathrm{TM}}$ HS offers superior specific strength, but it is more expensive, must be protected with a UV resistant coating, and production availability is limited. Further investigation into the properties of Spectra ${ }^{\circledR}$ revealed some limitations in airship applications. Spectra $^{\circledR}$ creeps under load, does not accept coatings for bonding seams and for laminating to non-porous films, and the seams cannot be welded due to loss of fiber orientation and strength at higher temperatures. ${ }^{18}$ Reference 19 details the use of coated Vectran ${ }^{\mathrm{TM}}$ HS fabric at 200 denier in the Mars Pathfinder Lander Air Bags. For Phase II it was assumed that Vectran ${ }^{\mathrm{TM}}$ HS would be used for the hull and ballonet fabric. Table 3 presents a performance summary for the

Table 3. Performance Summary for Phase II Concepts

\begin{tabular}{|l|c|c|c|c|}
\cline { 2 - 5 } \multicolumn{1}{c|}{} & Concept 1 & $\begin{array}{c}\text { Concept 1- } \\
\text { small }\end{array}$ & $\begin{array}{c}\text { Concept 5- } \\
\text { small }\end{array}$ & Concept 15 \\
\cline { 2 - 5 } & & & & \\
\hline Propulsion/Fuel Type & Fuel & & & \\
\hline TOGM Hurricane Science Mission (kg) & 4790 & 2270 & 2610 & 20380 \\
\hline Fuel Mass Hurricane Science Mission (kg) & 1460 & 500 & 970 & 4104 \\
\hline Endurance - Hurricane Science (days) & 8.1 & 4.0 & 4.0 & 180.0 \\
\hline Endurance - Communications Relay (days) & 10.0 & 5.6 & 5.0 & $36-180$ \\
\hline Average Transit Speed - Hurricane Science (km/h) & 250 & 260 & 234 & 103 \\
\hline $\begin{array}{l}\text { Average Transit Speed - Communications Relay } \\
\text { (km/h) }\end{array}$ & 188 & 190 & 173 & 140 \\
\hline
\end{tabular}
Phase II concepts.

The objective of the operational modeling task was to calculate the required fleet size for each of the Phase II concepts to meet both the hurricane science and communications relay missions over a twenty-year operational period. Estimates of required fleet size were needed to support the production and operations and support (O\&S) elements of the life cycle cost analysis. The overall mission requirement was to provide a single station of continuous coverage during the six months of the hurricane season while simultaneously providing continuous, yearround coverage of one station supporting communications relay. In addition to the vehicle characteristics in Table 3 , inputs to the operational concept model included the maintenance and attrition assumptions shown in Table 1. Fleet size estimates included spares and replacement vehicles.

For single vehicle or serial flight concepts of operation, the mission timeline begins with the first vehicle taking off and transiting to the area of interest to begin the loiter segment. When the fuel level requires a return to base (RTB), the first vehicle transits back and is recovered. In the single vehicle scenario, the total time on station requirement is met by the first vehicle and no additional flight operations are required. If the loiter endurance is less 


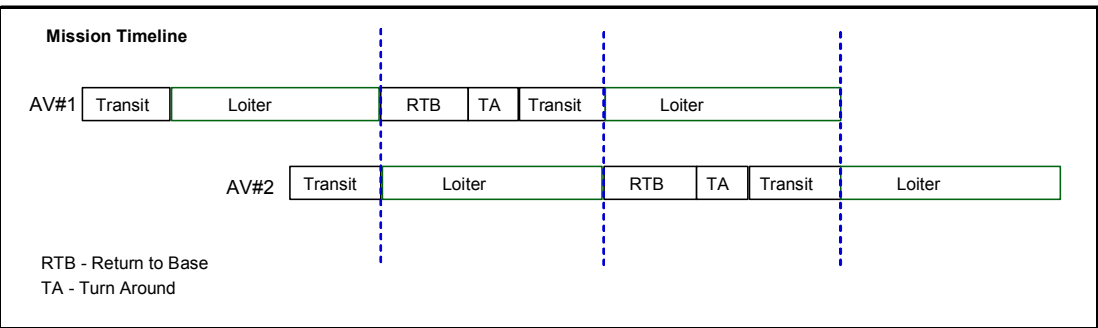

Figure 1. Two vehicle cycle to support a single station with continuous coverage. sum of the return to base transit time, the post-flight and pre-flight processing time ("turn around time"), and the out-going transit time, then this cycle can be supported with only two vehicles. A third vehicle is required if the loiter time is less than the sum of the transit times and turn around time. Figure 1 depicts this serial flight cyclical mission timeline for two vehicles, Air Vehicle 1 (AV\#1) and Air Vehicle 2 (AV\#2).

The outputs from the operational concept model that were utilized as inputs to the cost model included total number of vehicles required, number of maintenance actions required (A-check $=$ operational level maintenance and C-check $=$ depot level maintenance), total number of flight hours, and total fuel consumed. The totals for these parameters for both missions over the twenty-year operational period are presented in Table 4 for the Phase II concepts. The results show that the longer endurance vehicles result in smaller total fleet sizes; however, the relation between endurance and fleet size is not linear. That is, doubling the endurance does not correlate to a $50 \%$ reduction in the fleet size. Concept 1 has twice the endurance of Concept 1-small (8 days compared to 4 days), but only $20 \%$ more vehicles are required for the Concept 1-small fleet. Once the loiter time exceeds the transit times plus turn around time, the second air vehicle will sit on the ground ready

Table 4. Operational Modeling Results for Hurricane Science and Communications Relay Missions

\begin{tabular}{|l|c|c|c|c|}
\cline { 2 - 5 } \multicolumn{1}{c|}{} & Concept 1 & $\begin{array}{c}\text { Concept 1- } \\
\text { small }\end{array}$ & $\begin{array}{c}\text { Concept 5- } \\
\text { small }\end{array}$ & Concept 15 \\
\hline Propulsion/Fuel Type & & & & \\
\hline Total \# of vehicles & $\begin{array}{c}\text { IC Engine LH } \\
\text { Fuel }\end{array}$ & $\begin{array}{c}\text { IC Engine } \text { LH }_{2} \\
\text { Fuel }\end{array}$ & $\begin{array}{c}\text { IC Engine } \\
\text { Diesel Fuel }\end{array}$ & $\begin{array}{c}\text { Hybrid: LH } \text { P }_{2} \\
\text { PEM FC + } \\
\text { Solar Airship }\end{array}$ \\
\hline Total kg of fuel & 35 & 42 & 45 & 18 \\
\hline Total flight hours & $3,364,000$ & $2,557,000$ & $5,868,000$ & 270,300 \\
\hline Total \# of A-Checks & 525,400 & 628,900 & 686,500 & 441,200 \\
\hline Total \# of C-Checks & 768 & 935 & 968 & 101 \\
\hline
\end{tabular}

to launch and the cost effectiveness of additional loiter time is reduced. Furthermore, the cost of additional loiter time is high (a larger, heavier vehicle). The 4-day endurance vehicles do increase the total flight hours required and therefore have increased maintenance and attrition costs. However, the mass results indicate that Concept 1-small is much lighter and therefore should be less costly to procure than Concept 1 . Table 4 shows that Concept 15 , the hybrid PEM Fuel Cell + Solar Airship, has the smallest fleet size, total fuel required, total flight hours, and total maintenance checks. These benefits result directly from the long endurance of this design. However, the size and mass of Concept 15 will negatively impact the procurement costs. In addition, a simplifying assumption was made that the Concept 15 endurance for the communications relay mission did not vary with the time of year, which makes these results optimistic.

\section{B. Cost Analysis}

The purpose of the cost analysis was to obtain rough order of magnitude (ROM) life cycle cost (LCC) estimates to compare concepts on a relative basis. Producing an accurate cost estimate for an individual concept on an absolute basis is beyond the scope of this effort. Estimates were made for minimum, maximum (Max), and most likely cost. When available, actual cost data from vendors and previous NASA programs were utilized.

The cost estimating process followed a relatively simple flow which started with the creation of basic programmatic assumptions. The program schedule was assumed to begin with a two-year phase of risk reduction efforts performed by two competing contractor teams. Following the risk reduction phase, a single contractor would be competitively selected for full scale development, lasting five years, followed by a production phase, the length of which is concept dependent. Finally, a twenty-year period of mission operations was assumed. The LCC estimate was sub-divided along the traditional boundaries of Research, Development, Test and Evaluation 
(RDT\&E), Production, and Operations and Support (O\&S). The cost estimate was performed using constant year FY06 dollars.

The LCC analysis results are presented in Table 5. The values presented are the maximum values and therefore the most conservative, although at this early conceptual stage the cost uncertainty is high. Concept 1small and Concept 5-small had the lowest estimated RDT\&E costs, which correlates directly with their lower mass estimates. The estimates for total production costs are a function of the production quantities, production schedules, and concept mass estimates. The production quantity of Concept 15 is only 18 vehicles resulting in the lowest total production cost, even though the average unit fly-away cost is the highest. The O\&S cost estimates are similar for all four concepts. However, Concept 15 has a slight advantage in this category due to its minimal fuel consumption and fewer required maintenance actions. This lower O\&S cost, combined with the lower production cost, results in Concept 15 having the lowest overall estimated LCC. The HTA vehicle with the lowest estimated LCC is Concept 1 -small, followed closely by the diesel-fueled Concept 5-small. The estimated LCC of Concept 1 is significantly greater, proving that maximizing endurance for the HTA vehicles does not result in the most cost effective system given the mission and operational assumptions made to support this study. Another interesting result is the Max Operations (\$/flight hour) metric, which shows the diesel-fueled Concept 5-small to be the least expensive to operate at $\$ 291 /$ flight hour. This is due mainly to the relatively low cost of diesel fuel compared to $\mathrm{LH}_{2}(\$ 0.95 / \mathrm{kg}$ versus $\$ 5.20 / \mathrm{kg}$ )

\section{Solar Regenerative Mission Requirements Study}

In Phase I of the study, HTA SR concepts were analyzed for two sets of mission requirements that were deemed useful for communications relay and hurricane science. None of the concepts evaluated was able to perform either of the two missions. Since SR vehicles have been designed for multi-day flight in the past with current technology (such as the original AeroVironment Helios design), the existence of feasible combinations of mission requirements was expected. An SR mission requirements study was therefore conducted to provide more insight into feasibility across a broad range of mission requirements. A slightly refined version of Concept 7 was used as the study configuration. Because of the number of parameters defining the mission, and the ranges of interest for those parameters, performing an exploration of the mission trade space with a full analysis at each point of interest was

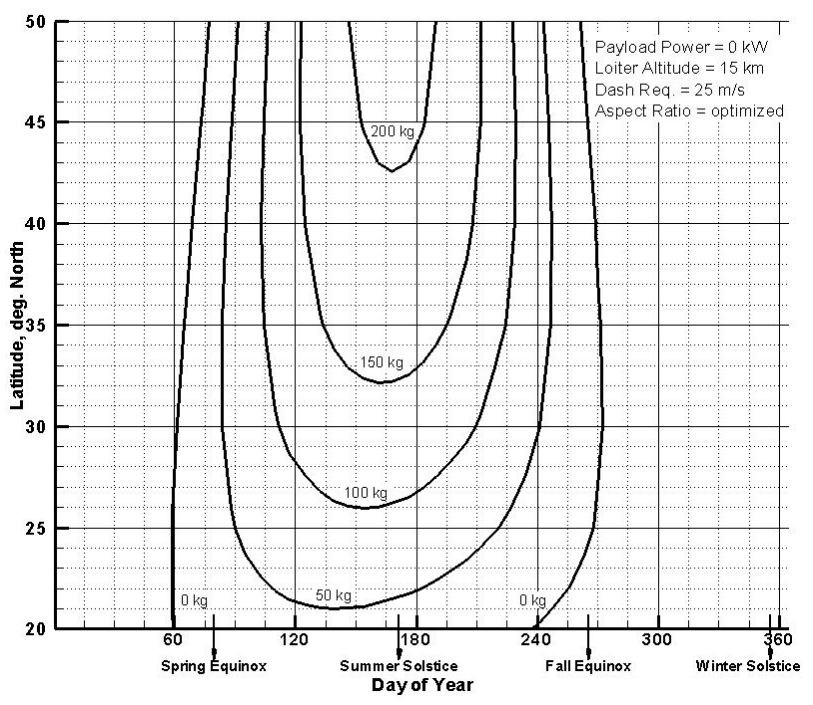

Figure 2. Latitude and Day of Year feasibility for various payload mass requirements. computationally prohibitive. To facilitate execution of the study within a reasonable amount of analysis time, a "meta-model" of the Concept 7 analysis model was developed using response surface methodology. Six mission requirement parameters were investigated: latitude, day of year, payload mass, payload power, loiter altitude, and minimum dash speed. In addition, the wing aspect ratio was optimized for each given set of mission parameters. Wingspan was held fixed at the assumed maximum span constraint of $100 \mathrm{~m}$ since based on prior results it was expected that this would be the optimum span. (With wing span fixed, the aspect ratio optimization was equivalent to a wing area optimization.)

A series of latitude and day of year "feasibility contours" for various payload masses is plotted in Figure 2. The feasibility contours are constructed from the set of latitude and day of year combinations for which $\% \mathrm{P}_{\text {regen }}=100 \%$ (the SR system is able to provide $100 \%$ of the power required to fly the vehicle based on a 24 -hour energy balance). The 
operational envelope for which feasible missions are possible encompasses the area "inside" these contours. Note that the contours in Figure 2 were determined with the other mission requirements set at the least stringent values considered in the study; a loiter altitude of $15 \mathrm{~km}$, a payload power requirement of 0 $\mathrm{kW}$, and a minimum dash speed of $25 \mathrm{~m} / \mathrm{s}$ (essentially no dash speed requirement). Year round capability is not possible at any latitude even with no payload and a loiter altitude of 15 $\mathrm{km}$.

In Figure 3 the feasibility of various altitude requirements are plotted against payload mass and power. The remaining requirements are set at their least tasking values (minimum dash speed $25 \mathrm{~m} / \mathrm{s}$, most favorable solar conditions of $50^{\circ}$ latitude on June 20). The maximum possible loiter altitude with no payload mass or power is $16.8 \mathrm{~km}$. A trade-off between payload

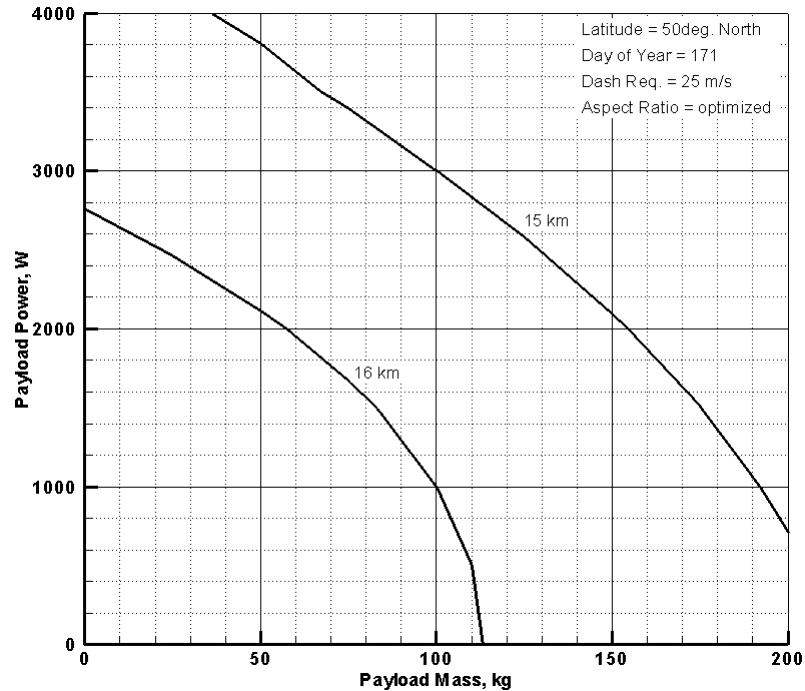

Figure 3. Payload Mass and Power feasibility for various altitude requirements. power, payload mass, and altitude capability is clearly evident from Figure 3. Increasing altitude $1 \mathrm{~km}$ reduces payload mass capability by roughly $100 \mathrm{~kg}$ or payload power capability by close to $2 \mathrm{~kW}$.

Given near-term technology assumptions and projections, it will not be possible for an HTA SR configuration to perform the hurricane science or communications relay missions defined for this concept study. In fact, mission capabilities are far from those required for the two missions. Utility in a communications relay application is severely hindered by the fact that year round capability is not possible at any latitude. Only missions which take advantage of the long days and short nights of summer to relax the demands placed on current energy storage system technology are feasible. Even at favorable solar conditions, payload mass and power have to be kept to a minimum to achieve feasibility. Despite latitude, time of year, and payload limitations, there may still be useful missions which could be accomplished with near-term SR concepts. A number of important scientific measurements can be obtained with very lightweight, low power payloads. And, there are likely scientific investigations for which the required mission timing and location match well with the vehicle capabilities. One example of a feasible mission is shown in Table 6, compared to the hurricane science and communications relay Phase II threshold missions. Such a vehicle would be able to operate in most of the continental United States during the summer months. There may be a number of scientific uses for this vehicle such as monitoring coastlines, in situ atmospheric sampling, wildfire detection, etc.

\section{Solar Regenerative Technology Study}

Table 6. Possible SR Concept Feasible Mission Compared to Desired Mission Threshold Values

\begin{tabular}{|c|c|c|c|}
\hline & $\begin{array}{c}\text { Hurricane } \\
\text { Science }\end{array}$ & $\begin{array}{c}\text { Communications } \\
\text { Relay }\end{array}$ & Feasible \\
\hline Loiter Altitude & $18 \mathrm{~km}$ & $18 \mathrm{~km}$ & $15 \mathrm{~km}$ \\
\hline Payload Mass & $200 \mathrm{~kg}$ & $136 \mathrm{~kg}$ & $50 \mathrm{~kg}$ \\
\hline Payload Power & $1.0 \mathrm{~kW}$ & $1.0 \mathrm{~kW}$ & $0.5 \mathrm{~kW}$ \\
\hline Dash Speed & $30.5 \mathrm{~m} / \mathrm{s}$ & $55.5 \mathrm{~m} / \mathrm{s}$ & $35 \mathrm{~m} / \mathrm{s}$ \\
\hline Latitude & $15-30^{\circ} \mathrm{N}$ & $25-47^{\circ} \mathrm{N}$ & $>30^{\circ} \mathrm{N}$ \\
\hline
\end{tabular}

The SR technology study was conducted to provide insight to the sensitivity of mission feasibility to technology advancements in various areas, and to determine the level of technology advancement required to make the hurricane science and communications relay threshold missions feasible. As with the mission requirements study, the number of parameters of interest for the technology study was too large to permit a full analysis at each point examined in the trade space. Response surface methodology was therefore used for this study as well. The technology areas considered were: solar cell efficiency, solar array mass, energy storage system roundtrip efficiency, energy storage system specific energy, airframe mass, and airframe drag. As with the mission requirements study, wing aspect ratio was optimized for each design and wingspan held fixed at $100 \mathrm{~m}$. For each mission "technology trade-off" charts were generated to show the sensitivity of mission feasibility to changes in technology assumptions. 


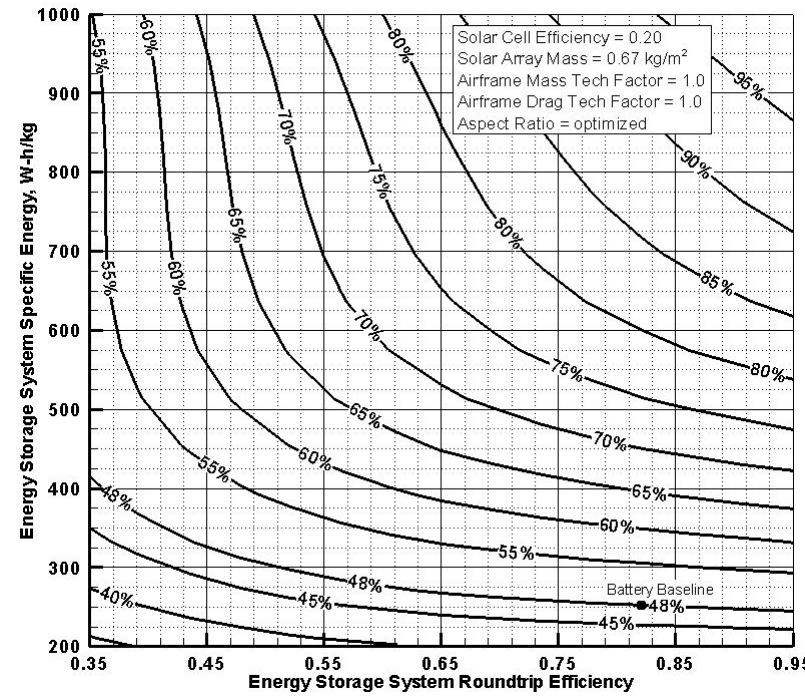

Figure 4. Variation of hurricane science mission feasibility with energy storage system technology.
Figure 4 shows an example of one of these charts for the hurricane science threshold mission. In Figure 4 contour lines of constant $\% \mathrm{P}_{\text {regen }}$ (feasibility) are plotted versus energy storage system specific energy and roundtrip efficiency. At the low specific energy of today's energy storage systems, feasibility is much more sensitive to increases in specific energy than improvements in efficiency. This is true not only at the relatively high efficiency of the baseline battery system (indicated by the dot on Figure 4), but also at the low efficiencies associated with regenerative fuel cell systems. There is a point, however, at which further improvement in specific energy has little value. For example, given a roundtrip efficiency of $50 \%$, similar to what might be achieved with a regenerative fuel cell system, there is little benefit from increasing specific energy above about $600 \mathrm{~W}-\mathrm{h} / \mathrm{kg}$. Above that point, feasibility is best advanced by improvements in efficiency. In reference 7 additional charts are provided for the solar cell, energy storage system, and airframe technology areas and both missions.

Solar cell efficiency and energy storage system specific energy were found to be the key propulsion system technologies for improving feasibility of HTA SR concepts. However, the best mix of technology investments and goals for SR aircraft research depends on the target mission (especially the latitude and time-of-year requirements). Missions requiring high latitude flight during winter are largely limited by the amount of solar energy that can be collected and benefit greatly from solar cell efficiency improvements. The ability to efficiently collect solar energy is less critical for missions in more favorable solar conditions, and in that case feasibility can be hindered by the mass associated with storing the energy that is collected. This important interaction between solar cell efficiency and energy storage system specific energy is examined more explicitly in Figures 5 and 6 . In these figures the variation in feasibility $\left(\% \mathrm{P}_{\text {regen }}\right)$ with combined changes in solar cell efficiency and energy storage system specific energy is shown for the hurricane science mission and communications relay mission, respectively. The technology assumptions for the other four technology areas (solar array mass, energy storage system roundtrip efficiency, airframe mass, and airframe drag) are held fixed at their baseline values.

Both figures illustrate several general trends. First, solar cell efficiency and energy storage system specific energy must both be improved to achieve substantial increases in mission feasibility. Second, for both technology areas there are regions of the trade space in which little or no increase in feasibility is obtained from further improvement. While these general trends apply to both missions, there are also some clear differences. The regions of "diminishing returns" differ for the two missions. In Figure 5 (hurricane science mission), at low specific energy the contour lines are almost horizontal, implying increases

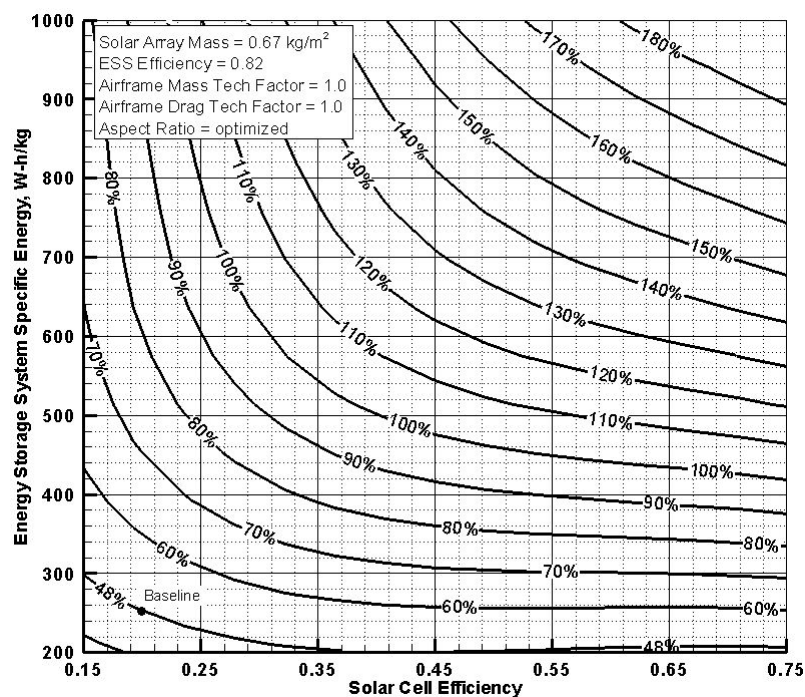

Figure 5. Variation of hurricane science mission feasibility with solar cell efficiency and ESS specific energy.

in solar cell efficiency have little impact on feasibility. The contour lines at low specific energy are more angled in Figure 6 indicating solar cell efficiency improvements do increase mission feasibility for the communications relay mission. At high specific energies, the contour lines become vertical more quickly in Figure 6 than in Figure 5. This indicates that the relative importance of solar cell efficiency versus energy storage system specific energy is higher for the communications relay mission than the hurricane science mission. The difference in the relative 
importance of energy storage specific energy and solar cell efficiency can also be observed by examining the increase in feasibility from improvement in just one technology area. Improvement in solar cell efficiency alone increases $\% \mathrm{P}_{\text {regen }}$ by $\sim 12$ points for the hurricane science mission and $\sim 22$ points for the communications relay mission. Improvement in energy storage system specific energy alone increases $\% \mathrm{P}_{\text {regen }}$ by $\sim 42$ points for the hurricane science mission and only $\sim 8$ points for the communications relay mission.

Another important difference between Figures 5 and 6 is the $\% \mathrm{P}_{\text {regen }}$ levels. For the hurricane science mission, the $\% \mathrm{P}_{\text {regen }}$ obtained from a combination of very high solar cell efficiency and very high specific energy is over $180 \%$. The same combination of technologies for the communications relay mission results in a $\% \mathrm{P}_{\text {regen }}$ of only $\sim 90 \%$, or in other words even with very high solar cell efficiency and energy storage system specific energy the mission is still infeasible. This is primarily due to the scarcity of available solar energy for high latitude, wintertime

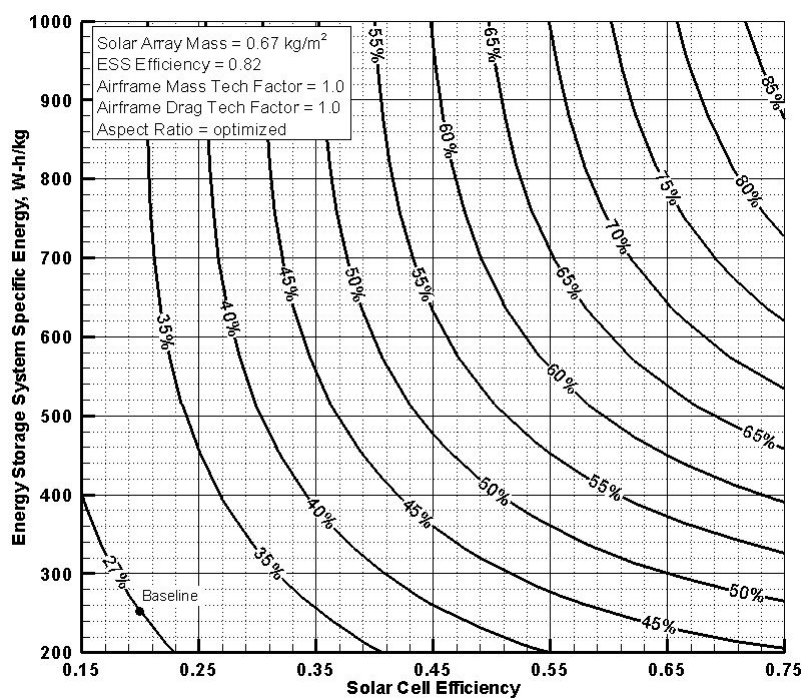

Figure 6. Variation of communications relay mission feasibility with solar cell efficiency and ESS specific energy. conditions.

In addition to examining the sensitivity of mission feasibility to technology assumptions, a set of hypothetical technology advances resulting in mission feasibility was determined for each mission. In reality there are infinite possible combinations of technology advances which will achieve mission feasibility. Table 7 shows a single combination for each mission. The values presented are not intended to be representative of any specific existing or envisioned technology. Note that the airframe drag and mass "tech factors" are simply multipliers which are applied to the values predicted in the analysis model. For example, a mass tech factor of 0.9 implies a technology has been applied which reduces that total airframe mass by $10 \%$ (for the same design gross mass, etc.).

Table 7. Hypothetical Advanced Technology Assumptions for Mission Feasibility

\begin{tabular}{|l|c|c|c|}
\cline { 3 - 4 } \multicolumn{2}{c|}{} & \multicolumn{2}{c|}{$\begin{array}{c}\text { Technology Set Enabling } \\
\text { Mission Feasibility }\end{array}$} \\
\hline Technology Area & $\begin{array}{c}\text { Baseline } \\
\text { Value }\end{array}$ & $\begin{array}{c}\text { Hurricane } \\
\text { Science }\end{array}$ & $\begin{array}{c}\text { Communications } \\
\text { Relay }\end{array}$ \\
\hline Solar Cell Reference Efficiency & $20 \%$ & $35 \%$ & $45 \%$ \\
\hline Solar Array Mass $\left(\mathrm{kg} / \mathrm{m}^{2}\right)$ & 0.67 & 0.80 & 0.40 \\
\hline ESS Roundtrip Efficiency & $82 \%$ & $90 \%$ & $90 \%$ \\
\hline ESS Specific Energy (W-h/kg) & 252 & 500 & 750 \\
\hline Airframe Mass Tech Factor & 1.0 & 0.90 & 0.75 \\
\hline Airframe Drag Tech Factor & 1.0 & 1.0 & 0.85 \\
\hline
\end{tabular}

For the hurricane science mission, improvement is primarily assumed in solar cell efficiency and energy storage system specific energy. The assumed solar cell efficiency of $35 \%$ is comparable to efficiencies which are currently being demonstrated in research laboratories. Array mass is assumed to increase to account for the extra mass typically associated with high efficiency cells. A modest increase in energy storage system roundtrip efficiency has been assumed, although the performance is fairly insensitive to this increase. The key technology assumption for this hypothetical scenario is a $500 \mathrm{~W}-\mathrm{h} / \mathrm{kg}$ ESS specific energy. This would require significant advances in battery technology. A specific energy of $500 \mathrm{~W}-\mathrm{h} / \mathrm{kg}$ would be easier to achieve with regenerative fuel cell technology, albeit at the expense of lower efficiency. A modest reduction of only $10 \%$ has been assumed for airframe mass and there is no reduction assumed in airframe drag. The technology assumptions required for the communications relay mission are more aggressive. The solar cell efficiency of $45 \%$ is beyond what has been demonstrated to date with multi-junction cells. Note that high effective efficiencies may be possible from combining the solar cells with other electricity producing elements such as thermoelectric cells, but such concepts lead to higher array mass. In the above technology set a reduction in solar array mass is also required in addition to the increase in efficiency. The simultaneous reduction in mass and increase in efficiency is counter to trends 
associated with current types of solar cells and array concepts. The required energy storage system has battery-like high efficiency with a specific energy greater than that projected for advanced regenerative fuel cell systems (having lower efficiency), and many times greater than current battery capabilities. Although the baseline airframe is already "clean" and very lightweight, the drag has been reduced by $15 \%$ and the mass by $25 \%$. It should not be inferred that there are known research efforts to achieve the technology levels assumed in Table 7 for the communications relay mission. These assumptions simply illustrate the extreme difficulty associated with meeting these mission requirements using a HTA SR platform.

\section{Conclusions}

A broad range of HALE UAV concepts has been evaluated relative to their application to two operationally useful missions, hurricane science and communications relay. A total of sixteen concepts were developed for the study, including heavier-than-air (HTA) and lighter-than-air (LTA) configurations with solar-regenerative (SR) and non-regenerative (consumable fuel) propulsion systems. A capability to perform technology and mission feasibility studies for HTA and LTA HALE UAVs has also been demonstrated.

None of the HTA consumable concepts examined can meet the threshold endurance requirement for either of the two missions. Concept 1 ( $\mathrm{LH}_{2}$-fueled IC engine propulsion) has the greatest endurance of eight days for the hurricane science mission and 10 days for the communications relay mission. The endurance capability of Concept 1 is nearly matched by Concept 3 ( $\mathrm{LH}_{2}$-fueled PEM fuel cell and electric motor). However, Concept 3 has higher risk, due primarily to the relatively complex and unproven propulsion system. Because the goal mission endurance could not be met with a single HTA vehicle, in Phase II of the study multi-aircraft operational concepts were examined. The operational and life cycle cost effects of a serial flight approach were compared for Concept 1 and two, "downsized" four-day endurance concepts. These four-day endurance vehicles, Concept 1-small (46 m wingspan, $\mathrm{LH}_{2}$-fueled IC engine) and Concept 5 -small (58 $\mathrm{m}$ wingspan, diesel-fueled), have lower estimated life cycle cost than the eight-day endurance Concept 1 . Given the mission and operational assumptions made for this study, the estimated life cycle cost of Concept 1 is significantly greater, proving that maximizing endurance for the HTA vehicles does not result in the most cost effective system solution.

All of the LTA concepts are able to meet the hurricane science mission goal endurance of 180 days and exceed the communications relay threshold endurance for most mission start dates. (LTA endurance is sensitive to mission start date due to seasonal changes in winds aloft.) The LTA concepts with the best endurance are Concept $11\left(\mathrm{LH}_{2}-\right.$ fueled IC engine) and Concept $12\left(\mathrm{LH}_{2}\right.$-fueled PEM fuel cell). However, the feasibility of operating the IC engine of Concept 11 continuously over the entire mission is questionable. For the communications relay mission, all of the SR LTA concepts (Concept 13, Concept 14, and Concept 16) are significantly larger and heavier than the consumable-fueled concepts. In addition, the risk associated with the SR concepts is higher than the consumable options. The performance of Concept $15\left(\mathrm{LH}_{2}\right.$-fueled PEM fuel cell plus solar array hybrid) is similar to that of Concept 12, but Concept 15 is smaller in size and mass. Compared to the HTA consumable concepts, Concept 15 has lower overall production cost since the production quantity is only 18 vehicles. Concept 15 also has lower operations costs due to its minimal fuel consumption and fewer required maintenance actions. This lower operations and support cost, combined with the lower production cost, results in Concept 15 having the lowest overall estimated life cycle cost of all the concepts.

None of the HTA SR concepts are feasible assuming near-term technology. That is, the SR propulsion system is not able to collect, store, and deliver a sufficient amount of energy to keep the vehicle aloft for a full diurnal cycle (24 hours). For the mission worst case solar days, the SR system is capable of providing at most half of the energy required. A mission requirements trade study was conducted which indicated that given near-term technology, HTA SR concepts are limited to missions consisting of minimally useful payloads and operation at mid to high latitude, summer conditions. Assuming HALE missions (altitude $>15 \mathrm{~km}$ ), wintertime missions are not possible at any latitude even with no payload. Solar cell efficiency and energy storage system specific energy are the key technology areas requiring improvement to enable enhanced mission capabilities for HTA SR vehicles. The technology advances required to enable the SR powered HTA vehicles for the threshold hurricane science mission are reasonable; such as, a solar cell efficiency of $35 \%$ (baseline was $20 \%$ ), an energy storage system specific energy of $500 \mathrm{~W}-\mathrm{h} / \mathrm{kg}$ and efficiency of $90 \%$ (baseline was $252 \mathrm{~W}-\mathrm{h} / \mathrm{kg}$ and $82 \%$ efficiency), and a $10 \%$ reduction in baseline airframe mass. Revolutionary advances are required, however, for the communications relay mission; for example, a combination of a solar cell efficiency of $45 \%$ accompanied by a $40 \%$ reduction in solar array mass, an energy storage system specific energy of $750 \mathrm{~W}-\mathrm{h} / \mathrm{kg}$ and efficiency of $90 \%$, a $25 \%$ reduction in airframe mass, and a $15 \%$ reduction in airframe drag. 
In the near term, the hurricane science and communications relay mission requirements can best be met with consumable propulsion systems. HTA SR concepts are not viable for these missions and for the communications relay mission SR propulsion greatly increases the size and mass of LTA vehicles with little performance benefit. Although LTA vehicles have the greatest potential for extreme, multiple month endurance, the mission requirements can also be met by serial flight of lower endurance vehicles. In fact, maximum endurance is not necessarily the optimum from a system risk and life cycle cost perspective. Balancing cost, risk, and performance, Concept 5 -small (HTA, $58 \mathrm{~m}$ wingspan diesel-fueled propulsion) is the best near-term concept.

\section{Acknowledgments}

The authors would like to thank the following researchers and engineers for their valuable contributions to this study: Mike Logan (NASA LaRC), Dr. Mark Motter (NASA LaRC), Paul Schmitz (Power Computing Solutions,

Inc.), Andrew Hahn (NASA LaRC), Ray Morgan (Morgan Aircraft Consulting), Cecile Burg (Georgia Institute of Technology), Melody Avery (NASA LaRC), and Steve Smith (NASA ARC). In addition, the authors appreciate the support provided by John Del Frate (NASA DFRC) and Fay Collier (NASA LaRC) which enabled the execution of this study.

\section{References}

${ }^{1}$ Hall, D. W., Fortenbach, C.D., Dimiceli, E.V., and Parks, R.W., "A Preliminary Study of Solar Powered Aircraft and Associated Power Trains," NASA CR-3699, December 1983.

${ }^{2}$ Youngblood, J. W., Talay, T.A., and Pegg, R.J., "Design of Long Endurance Unmanned Airplanes Incorporating Solar and Fuel Cell Propulsion," AIAA 84-1430, June 1984.

${ }^{3}$ Foch, R. J., and Ailinger, K.G., "Low Reynolds Number, Long Endurance Aircraft Design,” AIAA 92-1263, February 1992.

${ }^{4}$ Romeo, G., Frulla, G., Cestino, E., and Corsino, G., "HELIPLAT: Design, Aerodynamic and Structural Analysis of LongEndurance, Solar-Powered Stratospheric Platform," J. of Aircraft, Vol. 41, No. 6, Nov.-Dec. 2004.

${ }^{5}$ Colozza, A., "Initial Feasibility Assessment of a High Altitude Long Endurance Airship," NASA CR 2003-212724, December 2003.

${ }^{6}$ Atreya, S., Mata, M., Jones, R., and Kohout, L., "Power System Comparisons for a High Altitude Long Endurance (HALE) Remotely Operated Aircraft (ROA)," AIAA 2005-7401, September 2005.

${ }^{7}$ Nickol, C. L., Guynn, M. D,. Kohout, L. L., and Ozoroski, T. A., "High Altitude Long Endurance UAV Analysis of Alternatives and Technology Requirements Development," NASA TP (submitted for publication).

${ }^{8}$ Avery, M., Harrison, W., Velden, C., Hawkins, J., Vanek, M., Vipavetz, K., Guynn, M., Buccellato, S., Paddock, D., Qualls, G., "Decadal Survey Submission: An Autonomous Aerial Observing System for the Exploration of the Dynamics of Hurricanes," (unpublished), May 2005.

${ }^{9}$ Mankins, J. C., "Technology Readiness Levels: A White Paper," April 6, 1995. Office of Space Access and Technology, NASA, April 1995 (unpublished). URL: http://www.hq.nasa.gov/office/codeq/trl/trl.pdf [cited 12 December 2006].

${ }^{10}$ Moorhouse, D. J., "Detailed Definitions and Guidance for Application of Technology Readiness Levels," J. of Aircraft, Vol. 39, No. 1, 2002, pp.190-192.

${ }^{11}$ Ozoroski, T., and Mas, K., "A PC-Based Design and Analysis System for Lighter-Than-Air Unmanned Vehicles,” AIAA2003-6566, September 2003.

${ }^{12}$ Patterson, C., "Unmanned High Altitude Long-Endurance Aircraft," AIAA 89-2011, July 1989.

${ }^{13}$ Turney, G., "Fuel Cells for Propulsion of High-Altitude Aircraft," (unpublished), December 1989.

${ }^{14}$ Garcia, C., Chang, B., Johnson, D., Bents, D., Scullin, V., Jakupca, I., "Round Trip Efficiency of NASA Glenn Regenerative Fuel Cell System,” NASA TM-2006-214054, January 2006.

${ }^{15}$ Tudron, F. B., Akridge, J. R., and Puglisi, V. J., "Lithium-Sulfur Rechargeable Batteries: Characteristics, State of Development, and Applicability to Powering Portable Electronics," Sion Power, Inc., URL: http://www.sionpower.com [cited 12 October 2006].

${ }^{16}$ Gallman, J. W., Smith, S. C., and Kroo, I. M., “Optimization of Joined-Wing Aircraft,” J. of Aircraft, Vol. 30, No. 6, Nov.Dec. 1993, pp. 897-905.

${ }^{17}$ Honeywell Advanced Fibers and Composites, Spectra Fiber 2000 Product Specification, URL: http://www.honeywell.com/sites/sm/afc/spectra fiber.htm [cited 12 October 2006].

${ }^{18}$ Zhai, H., and Euler, A., "Material Challenges for Lighter-Than-Air Systems in High Altitude Applications," AIAA 20057488, September 2005.

${ }^{19}$ Cadogan, D., and Grahne, S. M., "Development and Evaluation of the Mars Pathfinder Inflatable Airbag Landing System," Paper IAF-98-I.6.02, presented at the $49^{\text {th }}$ International Astronautical Congress, September 1998. Available through Acta Astronautica, Vol. 50, No. 10, May 2002, pp. 633-640. 